\title{
Design and Implementation of Management System for Training Model of Sustainable Development
}

\author{
Lin Zhou \\ Qingyuan Polytechinc, P.R.China \\ qyzhoulin@163.com
}

\begin{abstract}
Keywords: The sustainable development, Personnel training mode, The management information system

Abstract. To achieve the management systems of vocational school's training mode for sustainable development, we developed it with the .NET and using ASP.NET, SQL Sever2000 database and so on for designing, by building a information system of sustainable personnel training mode, analyzing each component of management systems, constructing the framework of management system and discussing the implementation of database and the security. This management system has certain significance for improving the level of information and the ability of data analyzing in vocational training.
\end{abstract}

\section{Introduction}

Most colleges and universities record students' various data by some independent management information system, such as, the admission system for the data of students' enrollment; the educational management system for students' activities and achievement in learning; the quality development system for the related activities; intern system for internship situation; and the graduates dynamic system for tracking and managing the latest working dynamic of each graduate. However, each system is independent from each other without unified management, which usually could lead to "Data Fighting". ${ }^{[1]}$ In order to change the current situation, the article constructs the management system of vocational school's personnel training for sustainable development by unifying the enrollment information module, the students' performance module (including courses and quality activities), the graduates dynamic tracing module (including working routes and the companies), and the statistics and analysis module (analyzing the different performance after graduation), which provides objective and comprehensive scientific basis for subsequent personnel training in polytechnics.

\section{Information Model}

\subsection{Sustainable Development Training Mode Information Model}

By recording the student's work situation and the situation after the school performance of students graduating, and two items of data records for statistical comparison and analysis to get some meaningful data, such as better student achievement classmates and lower computer salary difference after scores of students graduating large, so later in the development of a training program to strengthen the teaching and practice of the computer; data discovery through post-graduate student materials enhance the sharpest wage, schools should increase material professional software and hardware investment can strengthen the publicity at the time of enrollment. Students in the school of information, records, and these two types of statistical information and analysis of the situation of students after graduation, obtained in accordance with the revised training program (Fig 1). 


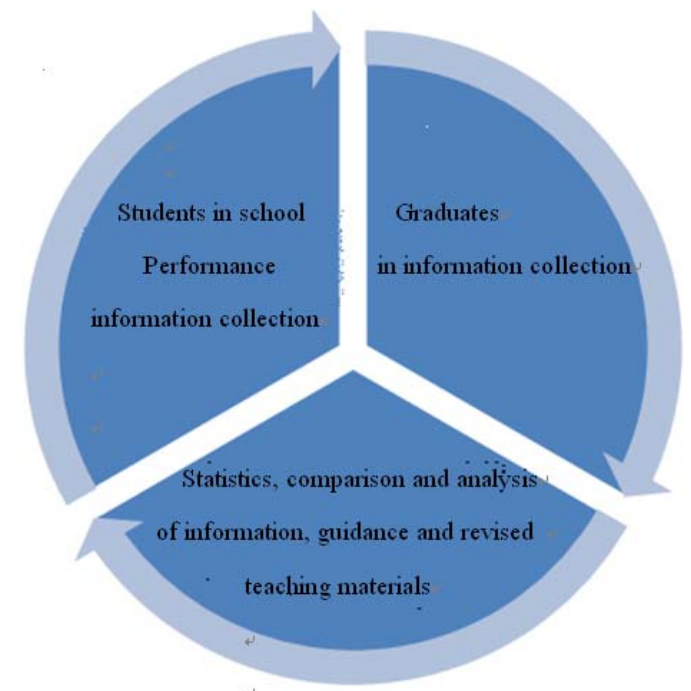

Fig1: Information Model Training Model Sustainable Developmen

1.2 Constitute training model management system for sustainable development Constitute training model management system (Fig 2) sustainable development.

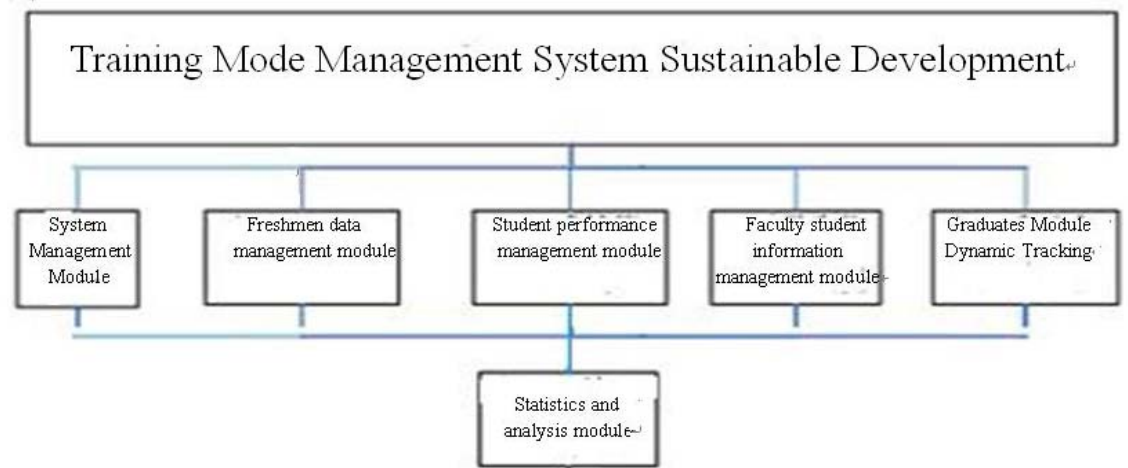

Fig2: constitute the Sustainable Development Training Model Management System

\subsubsection{System Management Module}

This part of the functions performed by the system administrator user to manage and maintain the platform, including user to add, delete, rewrite and query operations, user permissions are configured, the system data backup and restore management, BBS management.

1.2.2 Neonatal data management module

The main module is managed by administrators and admissions staff relevant information and data on the newborn, including by administrators to import data newborn, neonatal admissions office staff additions and deletions to data, data queries of newborn and neonatal data statistics and other operations.

1.2.3 Student achievement management module

Student achievement Management module can achieve a better import of student achievement, student achievement input, student achievement conventional CRUD operations, and student achievement statistics, student achievement query.

1.2.4 Faculty student information management module

Faculty student information management module by faculty administrator students basic information and comprehensive information to add, delete, and query rewrite and statistical management.

1.2.5 Dynamic Tracking Module

Graduates tracking module completed graduate employment information into graduate employment information to add, delete and change, workplace maintenance, student employment statistics and information inquiries.

1.2.6 Statistics and Analysis Module 
The main function is to achieve partial analysis of information and statistical functions, such as professional and statistical analysis, source region and analysis by students, according to the working units and statistical analysis of each student state characterized by low student achievement statistics salaries after graduation, according to students participate in school activities and statistical analysis of student promotion and changing of the guard situation.

\section{Design and implementation of management systems training model for sustainable development}

\subsection{System Architecture Design}

The overall framework of the system was designed in accordance with the three-tier model (Fig. 3), the first layer is the client service layer, any user can access to the Internet workstations can log in to browse, or back-end systems management ${ }^{[2]}$; the second WEB server layer, business logic layer; a third layer for the database service layer, typically a database server running on a separate server, WEB server, and when separated architecture, which can improve the security of the entire system. Front page to access the database through ADO connection, C \# ASP.NET development as the main language, is mainly used to handle server-side events, in order to increase the processing speed response, the client uses an interactive web development technologies (Asynchronous JavaScript and XML, Ajax) and Javascript development.

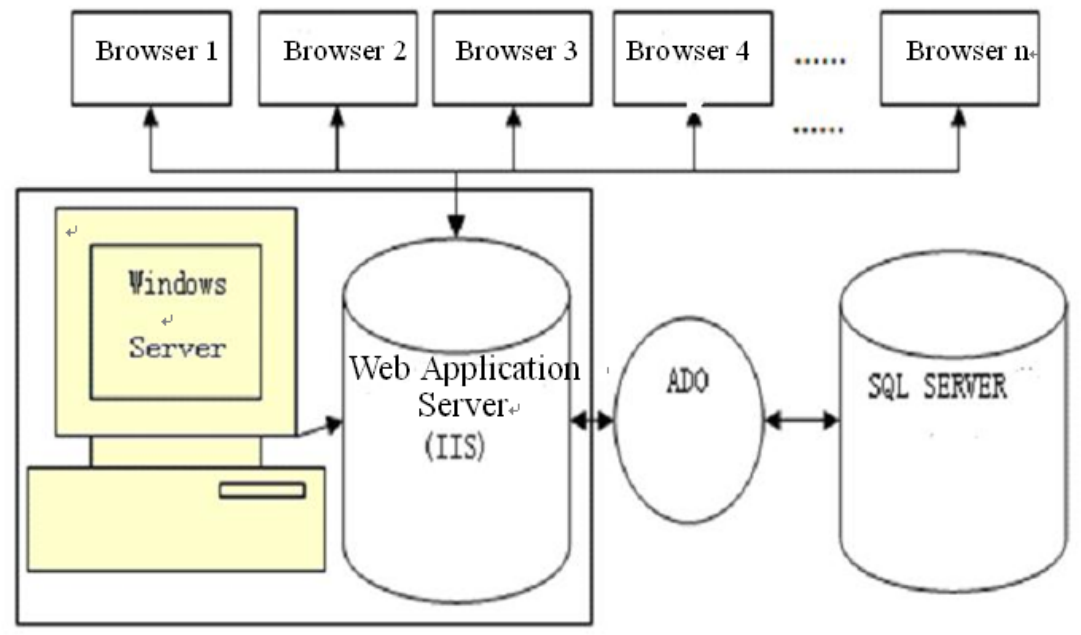

\subsection{System Functional Design}

Fig3: System Architecture

System in accordance with the principle of high polymer, low coupling of the entire management system to be divided, divided into the following six modules.

\subsubsection{System Management Module}

User Management: The system administrator has the highest authority of the system operation, it is convenient for the user additions and deletions.

User rights management: different users to assign different permissions, including faculty grant administrator, enterprise administrator permissions granted.

Data backup and restore system: the use of features and manual database backup automatic backup method of combining data backup system, this can better ensure data security.

Notify management: the school's high school students and teachers as well as the business side administrator issued a notice to inform the management and publishing.

BBS management: you can easily manage the Forum, such as post queries, remove postings on the forum content.

2.2.2 Neonatal data management module

Import data and transaction management newborn: This function module can be more convenient to import data newborn, not a one of the input data newborn. 
CRUD operations newborn data: This function block can be more convenient to record and modify all new sources of city, school, family, arts and sciences, the specialty, newborn college entrance examination scores and the like.

Freshmen Data Query: can easily query the source of any case of a classmate, and support fuzzy search.

Freshmen statistics: statistics can be more convenient freshmen meet a condition characteristic of freshmen accounted for the situation, as can be more convenient source of statistical freshmen were cities, towns, rural students accounting situation and specific data, arts and science students accounted situation and specific data, the average student admitted to the professional college entrance examination scores.

2.2.3 Student achievement management module

Students in school achievement Import Management: can be more convenient to use this function to import students from the Senate sub-module system, school grades, after the post-card system can achieve shared student achievement.

Student achievement CRUD operations: This function module for students of all subjects in school maintenance, such as increasing student achievement, modify a student's achievement in a course like.

Student achievement query: This function block is used to come to school to learn all the students attended a performance of the query operation, and support fuzzy queries.

Student achievement statistics: This module can function on student achievement data to classify all the statistics and analysis, such as a course of several parallel classes average, compare the average score for all first-year and sophomore course of a.

2.2.4 Faculty student information management module

Department administrators can use this module information acquisition and management of the faculty student information.

Students basic information management: This feature can be very convenient sub-module collection and management of basic information for each student.

Students' Comprehensive case management: This sub-function modules can be more convenient for the students in the school records of the situation and increased query and modify operations.

Students' Comprehensive statistical information and inquiry: This function module can be easily in class, faculty, professional, gender and other classified statistics and analysis.

2.2.5 Dynamic Tracking Module

Results of student internships input: This function module is used for students' practice performance management and recording.

Graduates enter the workplace where student performance: this function simulates the information officer of the employer input student performance.

After graduating students work unit input of new students pay: this function module by the employer to the information inputs of the unit's work student wages situation.

2.2.6 Statistics and Analysis Module

According to the students' professional statistics and analyze student performance and remuneration: Remuneration relations can be classified statistics graduate student by student and professional expertise, pay diagram.

Statistics by students of Origin and analyze student performance: this function module by students of Origin statistical classification.

Statistical analysis by the students in the workplace performance of different units, the analysis should allow us to train and to the corresponding enterprises after graduation what kind of talent.

\subsection{System analysis use cases}

Training model of sustainable development management system involves vocational colleges users: system administrators, faculty administrators, business users, graduates. Graduates user object to an example (Fig.4), the main function of the sustainable development of higher vocational colleges Training Model Management System graduate has the following: 
(1) graduates registered by the system administrator complete, the system administrator will register to post graduate or import data into the system graduates have been completed.

(2) personal data maintenance, including maintenance during the school students basic information, such as CRUD operation, the status of graduates after graduation information dynamically record industry graduate working conditions and performance information is recorded in the unit.

(3) business management graduates and graduates Login Forum Forum to view or publish information.

(4) Comparison of graduates now work, you can view the personnel needs and requirements of additional information provided by the company.

(5) Serving CV.

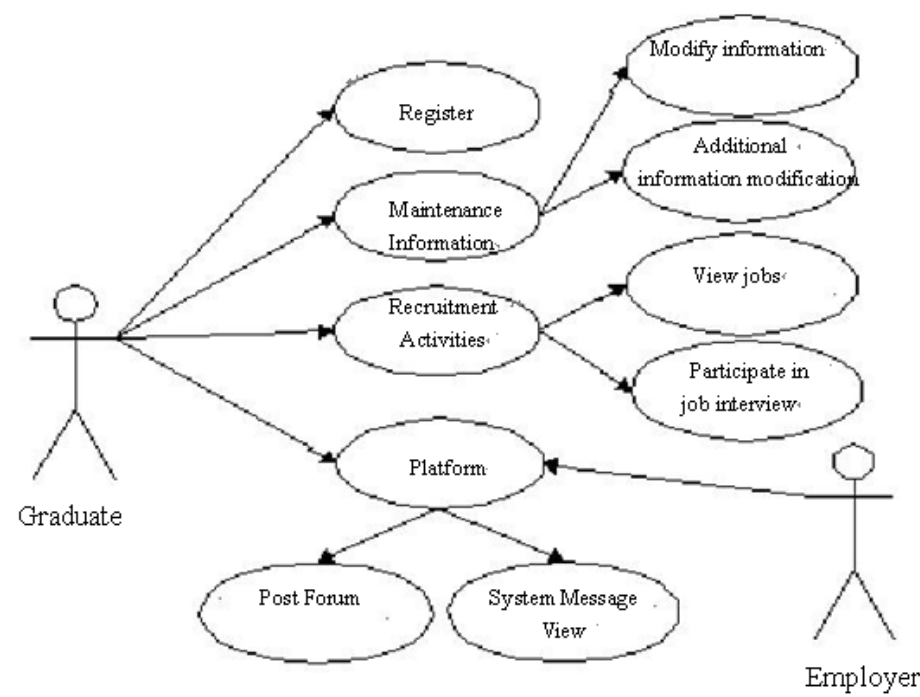

Fig4: Graduates use case diagram

\subsection{Database Design}

To construct the optimal database structure model $^{[3-5]}$, relationships generate database tables, queries, views, and triggers allow users to make additions and deletions to the database operation can be fast and accurate response of the system designed multiple data tables. Data tables are used to store various information departments, professional information, class information, student basic information, information on student achievement, student internships and employment information, employer information, course information students, teachers, and other information. Table1 shows the evaluation for graduates overall information table, space is limited, other data table design can not be listed.

Tab1: Students' Comprehensive evaluation information table

\begin{tabular}{|c|c|c|c|c|}
\hline Field name & $\begin{array}{c}\text { Data type / } \\
\text { length }\end{array}$ & Is empty & $\begin{array}{c}\text { Whether the } \\
\text { primary key }\end{array}$ & Field Description \\
\hline Stu_no & Char(11) & Not null & Yes & student ID \\
\hline Stu_name & Char(10) & Not null & No & Ability \\
\hline Op_skill & Char(30) & Not null & No & Professional basis \\
\hline Pro_skill & Char(30) & Not null & No & $\begin{array}{c}\text { Foreign language } \\
\text { proficiency }\end{array}$ \\
\hline English_skill & Char(30) & Not null & No & Creativity \\
\hline Computer_grade & Char(30) & Not null & No & Integrity Quality \\
\hline Cre_skill & Char(30) & Not null & No & Teamwork \\
\hline Honest & Char(30) & Not null & No & Time management skills \\
\hline Coorper_skill & Char(30) & Not null & No & Communication skills \\
\hline Time_skill & Char(30) & Not null & No & Writing skills \\
\hline Com_skill & Char(30) & Not null & No & Comprehensive Quality Level \\
\hline Write_skill & Char(30) & Not null & No & No \\
\hline Gen_skill & Char(4) & Not null & &
\end{tabular}




\subsection{System Security Design}

System design process there is a very important design process is the safety design of the system. Web-based management information system in the security aspects of the system is mainly reflected in two aspects of database security and network security. Information in the database management system, all data are stored centrally in the data server and shared by all users, security of data in the database is particularly important.

Security Design Training Mode security management system includes a server and database security for sustainable development, the use of database security role to implement secure access control system, a user has permission to operate a data by the access control method to achieve. When users $\log$ in, the system will let users determine their own identity, different users have different access rights to the data, the system determines the difference this user is a legitimate user or unauthorized users, such as "yes" then you can have the relevant databases access to, such as "NO" you can not access the relevant database. In the access control database, we generally will now access control is divided into: mandatory access control model and discretionary access control. With the current hardware and software technology continues to develop rapidly, growing popularity of Internet technology, network size huge benefits, increasing the user data, the arrival of the era of big data, type mandatory access control and discretionary access control database access control management It will become very complicated and very unsafe. Role-based access control access control technology (Rule-Based Access control, referred RBAC) can better resolve forced type access control and discretionary access control existing problems. RBAC role access control model consists of three entities constituted, including users, roles and permissions [6]. The user is the owner of the body or authority permission. A role is a specific and detailed classification in an event in the organization of the work. Permissions are resources operations and resource access permission operation, such as a database table read and write operations, renaming, deletion, and the phase of the database should be operating authority.

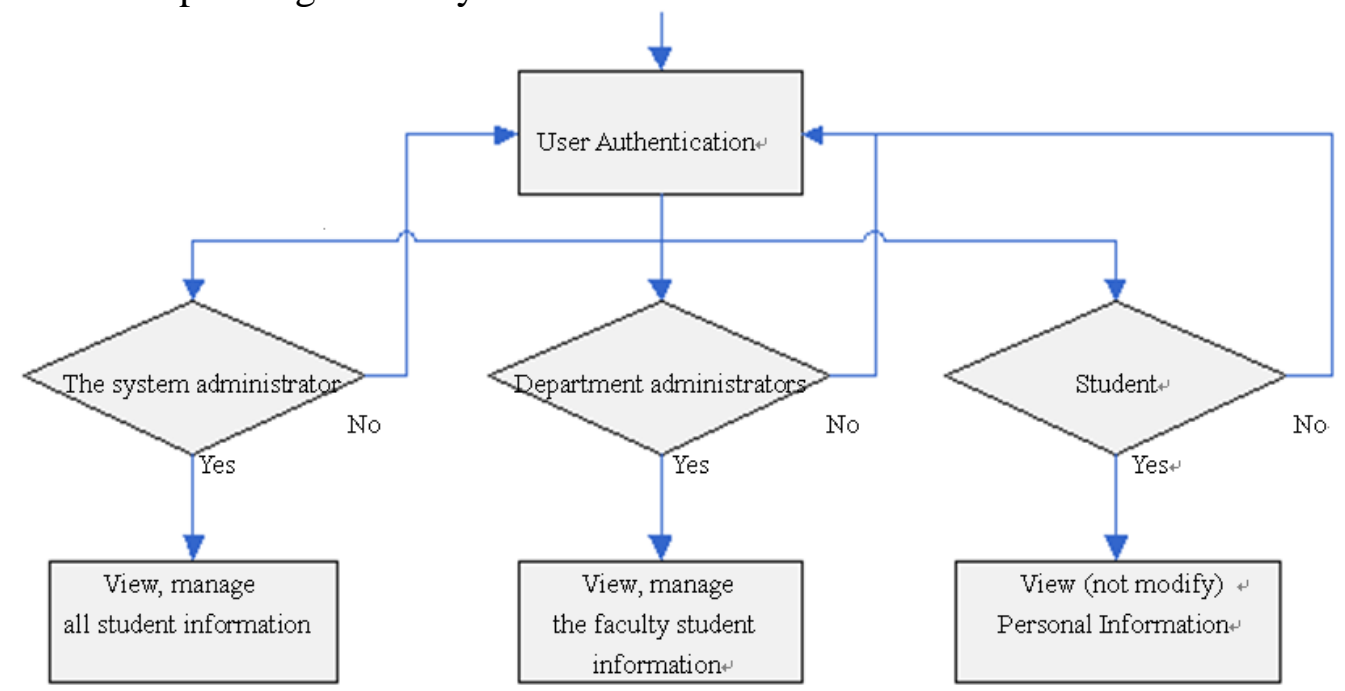

Fig5: Different data sources accessed by the user

\section{Summary}

This paper starts from the requirements of analysis training model of sustainable development, in strict accordance with the development of planning process of software engineering, use prototyping and development methods for users, combine with hierarchical architecture design, use ASP.NET, C \# language, SQL Server2000 database management system to achieve the management system on the platform of .NET. This system has some modules including user information management, students information management, intern management, graduates dynamic tracking, which manage the data easily, and then provides the basis for decision making in personnel training. The successful running of this system achieves the scientific tracking management, collecting and analyzing data, which 
provides a good data support for sustainable personnel training in our school and other vocational colleges.

\section{References}

[1] Department of Higher Education. Personnel training level assessment at higher vocational colleges . People Post Press. 2012.4

[2] X. J. Sun. Design and Implementation of B/S structure of the test system based on [J]. Silicon Valley, 2013(1):56,62.

[3] M.X.Ma. Based on research ASP.NET + SQLServer database management system of teaching quality[J]. Journal of Aerospace Medicine,2012(9):1142-1143.

[4] G.Y.Shi and F.Qiao. Achieve extended information system database with ASP and SQL SERVER[J]. Chinese e-commerce,2011(7):55.

[5] Q.R.Dai. Design and implementation of ASP.NET technology network teaching platform based on[J]. Journal of Fujian Radio \& TV University, 2012(6):57-61. 